\title{
A Study on the Attitude of Parents, Teachers and Adolescents towards Social Networking Sites
}

\author{
Anjali Shokeen', Avni Jain² \\ ${ }^{1}$ University School of Education, GGSIP University, Dwarka, Delhi, India \\ ${ }^{2}$ Research Scholar, GGSIP University, Dwarka, Delhi, India
}

\begin{abstract}
Social Networking sites have the most popular medium for the exchange of information and knowledge across the globe. There has been a flood of Social Networking Sites in the last five years. The younger generation makes most of the use of social media than any other demographic. Students especially use such medium to stay in touch with old friends and also to meet new ones. Adolescents have been the first ones to embrace social media platforms and have been mainly responsible for the popularity of such platforms. The impact that social media can have on adolescents is very critical and poses important questions for educationists. The exponential increase in mobile ownership in the last few years has further increased the number of social media avenues and the usage of social media by adolescents. With the increasing number of cases of cyber bullying, clique formation etc., the researcher believes this study is relevant to the current times and will attempt to answer questions which are critical to understanding the attitude of adolescents along with their parents and teachers towards Social Networking Sites. The research has been conducted on Adolescents of 16 years of age and their Parents and Teachers respectively with a view to know their Attitude towards Social Networking Sites. The study was conducted on 100 Adolescents, 30 Teachers and Parents through Likert scale and Questionnaire.
\end{abstract}

Keywords: Social Networking Sites, Adolescent

\section{Introduction}

In recent years, the use of Social Networking Sites has grown excessively specially among the adolescents. Adolescence is a time of life that is both inspiring and discouraging. It can be frantic with excitement and regret, self-confidence and insecurity, companionship and loneliness. Social media has opened many options for learning and knowledge processes. Many of the students use Social Networking Sites for educational purposes also.

In the technological changes, Internet is a strong evolutionary force which has vibrated almost all domains of social, personal and professional human life. These developments in the internet applications are beyond our imagination. Social Networking Sites helps in reconnecting with old friends, Adolescents can use network of online friends and remains keeps in touch with each other. They can establish social relationships, social networking members by joining groups and forums. This network helps in getting jobs and also a great help in establishing business contacts. The growth rate of Social Networking Sites demands the teacher and parental monitoring of adolescents users. This is the focus of attraction of researchers and the academicians towards this occurrence.

These days, Social Networking Sites are one of the most important ways of communication among the Adolescents. Participation of Adolescents in online Social Networking is a source for securing support, approval and friendships for an Adolescent. The Study on the attachment patterns of Adolescents' unveils the use of Social Networking Sites for informal attachments among more socially distant people by traversing the social gaps. This wave of technology is influencing the new generation of communicators starting with the Adolescent scholars. Most of the Adolescents' are not aware of that how posting something that is personal or even posting something that is improper can compromise their security.

The expansion of Social Networking Sites and their pervasion in everyday practices is influencing the management of social networks of Indian youth .In less than a decade, these sites have grown from a basic online activity into a process through which millions of internet users are connected, both in their free time, and at work. There are many factors that have been responsible for the consideration of the implications of these technologies for policy-making. One of these is the inclination of users to accept Social Networking Sites as a means of communication and social networking in day-to-day life.

In addition, the boom in mobile technology has meant that most Adolescents have easy access to smart phones. In addition to the websites, increasingly there are mobile apps such as Instagram, P interest, 9gag, etc. which has caught the fancy of the Adolescents. Adolescents are usually keen to try out new social networking methods and these apps have given them the right tools to enter into new social networks with both existing friends and new virtual friends.

Social aspects like family structure, parenting style, family participation, and communication among family members play a pivotal role in the Adolescents' usage of social media. Correct style of parenting serves as a catalyst for balancing the socio-emotional needs of the Adolescents, which may have otherwise been fulfilled through the use of social media. Adolescents are at a risk due to their tendency to experiment with social media, as a result of peer pressure and limited self-regulation capacity.

In today's world, there are many crucial issues around us which needs to be thought and action to be taken like Crime against women, Corruption, Violation of human rights, Education, Global warming etc. These issues need to be 


\section{International Journal of Science and Research (IJSR) \\ ISSN (Online): 2319-7064 \\ Index Copernicus Value (2013): 6.14 | Impact Factor (2014): 5.611}

discussed with the society for bringing revolution. Social Networking Sites provides a platform where one can discuss these issues. They can share their opinions through discussion threads, polls and forums. These networking sites are very positive aspects in many ways but they have negative effects too. Cyber crime is an example which has become threat to the people worldwide. It has ended up as a hallucination_for a few people. Moreover Social Networking Sites influences the attitude of Adolescents towards a happening of an event.

\section{Literature Review}

In the past several years, the use of Social Networking Sites has increased which has become an international issue. Due to increased technology usage for communicating with others, 'Social Networking' has become a primary activity on the internet with the sites like Facebook, Myspace, Twitter etc. A research conducted in United States showed that approximately $90 \%$ teenagers have internet access and approximately $75 \%$ of these teenagers use internet more than once in a day. The study also showed that approximately $50 \%$ teenagers who have internet access, are also members of Social Networking Sites and they make plans with their friends through internet (Kist, 2008) ${ }^{1}$.

Tuckman (1975) $)^{2}$ also revealed that use of technology such as Social Networking Sites through Internet is one of the most important factors which affects educational performance positively or adversely of the students.

Shah $(2001)^{3}$ proposed that students are affected by the use of internet and this is determined by the type of internet usage. By the informative use of internet, they are positively affected while using as recreational usage of internet, they have drastic impact on them.

Jain (2012) ${ }^{4}$ revealed that Social Networking Sites are acting as a means for mobilization. People feel free in sharing their thoughts on various issues. Even Adolescents raise their voice against social acts like Corruption, Reservations, and Violation of human rights. Social Networking Sites are successful in providing a platform where people can share their views on these social issues.

Mehmood (2013) ${ }^{5}$ concluded that students had started using social networks for academic purposes. Moreover they use online networks for writing their assignments given by the teachers, while some students viewed Social Networking Sites as a distraction and they hesitate to share their feelings. Most respondents found that Social Networking Sites are an avenue for searching information; educational networks and also they look for career opportunities.

Mahat (2014) ${ }^{6}$ revealed that Social Networking Sites are providing platform for giving suggestions on various social issues. Adolescents are getting more aware about social issues through Facebook. One should focus on ethical use of these Social Networking Sites because it serves the society in a right way. Adolescents can play an important role in society as Social Networking Sites are boob and curse for the Indian society.
Patil (2014) ${ }^{7}$ revealed that parents should have a transparent a real two way communication with their children so that they can establish a safe and a positive relationship with them. Students use Social Networking Sites for various social activities and for writing class assignments given by the teachers. Moreover, Findings of the study suggested that despite spending time on the Social Networking Sites, students were efficient in their studies. They did not face difficulty in academic performance.

Cline (2012) ${ }^{8}$ concluded that considering both the advantages and disadvantages associated with adolescent use of social media, parents and teachers cannot afford to keep an ignorant attitude and avoid to engage in a conversation with each other and adolescents about the impact that online environment has in their lives. There is a high degree of risk involved in the use of Social Networking Sites. The role of monitors, guides and educators is very crucial in leading the adolescents towards not only self-development, but also the development of the families and communities.

\section{Objectives of the study}

1) To explore the usage tendency of Social Networking Sites by Adolescents.

2) To know the attitude of Adolescents towards Social Networking Sites.

3) To gauge the attitude of Teachers towards adolescent's cyber tendencies.

4) To gauge the attitude of Parents towards usage of Social Networking Sites by Adolescents.

\section{Methodology}

The present study is descriptive in nature. In this study, the primary data is used for the data collection. The primary data for this research study was collected through Questionnaire and Likert scale. The researcher developed the Questionnaire for students and Likert Scale for students, teachers and parents. Questionnaire for students was developed to elicit the usage tendency of adolescents towards social networking sites. It was ensured in Questionnaire that the questions that were open-ended were eliciting a descriptively rich data.

Likert scale for students comprised of 20 evaluative statements concerning adolescent's outlook about Social Networking Sites. Both favorable and unfavorable statements were formulated covering various parameters like Social acceptance, Learning, Adjustment, Exposure and Frequency of visiting Social Networking Sites. Likert scale for teachers comprised of 20 evaluative statements concerning teachers viewpoint about Adolescent's cyber tendencies on the basis of the various parameters like Social interaction, Social acceptance, Awareness, Skill development and Communication between student and teacher via Social Networking Sites, items were formulated for Likert scale. Likert scale for parents was formulated to know their opinion about adolescent's cyber activities. The items were formulated on basis of the parameters like frequency of visiting Social Networking Sites, Social Networking Sites content, Purpose behind visiting Sites, Privacy policy and Worthiness of Social Networking Sites. 


\section{International Journal of Science and Research (IJSR) \\ ISSN (Online): 2319-7064 \\ Index Copernicus Value (2013): 6.14 | Impact Factor (2014): 5.611}

\section{Population and Sample of the study}

The data of Questionnaire was collected from 100 respondents. The population of the present study includes Adolescents of age 16 years of all the schools of East Delhi, Parents of these Adolescents and the teachers teaching them. For the purpose of present study, purposive sampling technique was adopted. The sample for the present study includes Adolescents of 16 years of age of three schools of North East Delhi. Thirty teachers of senior secondary level constitute the sample of the study, which was chosen through random sampling technique, ten teachers each from the three selected schools were chosen for the sample of the study. Thirty parents of adolescents of sixteen years of age constitute the sample of the study, which was chosen through random sampling technique.

\section{Analysis and Interpretation}

The first step in analyzing qualitative research involves organizing the data. After data collecting, the whole data was analyzed by the frequency tabulation and percentage analysis. Qualitative research often results in voluminous notes from Questionnaire and Interviews. The attitude scale was analyzed through totaling the frequency of responses. The responses were then converted to percentage score each of the twenty statements; the responses were then divided for each category. Interpretation of each statement was done for all the three Likert scales. The questionnaire was analyzed by calculating the percentage of responses for each question for close -ended questions and content analysis was done for open-ended questions.

\section{Findings and Conclusion}

The analysis and interpretation of raw data led to a number of findings pertaining to the research work under taken. Hundred percent of the adolescents use Social Networking Sites mainly through their smart phones. The claimed awareness about the privacy terms and conditions of the adolescents is hundred percent, but still they provide partial information on their profile. Adolescents visit Social Networking Sites everyday but spend less than one hour a day. Adolescents have more than three hundred friends but are cautious about friend requests from strangers. Adolescents mainly use Social Networking Sites for chatting with friends and believe that Social Networking is seriously affecting their studies but their face-to-face communication is getting affected to some extent only. Adolescents claimed that their parents are aware of their usage of Social Networking Sites. The privacy policies are effective but still adolescents face offensive comments some times. Adolescents were of the opinion that Social Networking Sites help them in development of their communication skills. A day without Social Networking Sites will be very boring and depressing according to adolescents, this shows their dependency on Social Networking Sites.

The Adolescents have a neutral attitude towards Social Networking Sites. Social Networking Sites help Adolescents in maintaining their social relationships, bonds with peers, keep them updated with new information and make them a member of the global family. Due to high frequency of visit to Social Networking Sites Adolescents are not able to strike a balance between their real and virtual world resulting in less family interaction and higher stress level. Adolescents agreed that extensive use of Social Networking Sites might lead to antisocial activities so they need to update their awareness about the antisocial activities prevailing through Social Networking Sites. Adolescents were of the opinion that they are able to choose their privacy settings but do not feel safe about the information they provide.

Teachers agreed that Social Networking Sites presents a platform for discussion between teachers and students. Teachers believe that most of the adolescents are not aware of the purpose of creating a Social networking account and moreover most of the Social Networking accounts are a result of peer pressure. Teachers opined that students are not able to strike a balance between Social Networking Sites and academics. The Social Networking Sites do not play any significant role in the development of skills, according to the teachers. Teachers were of the opinion that students believe that Social Networking Sites are the only means of social acceptance. Teachers opined that students should not be able to access a teachers' complete profile and in a similar manner teacher's access to students' profile should be limited.

Parents agreed that social networking Sites help their wards in keeping updated and becoming a member of the global community. Parents do not hold any worthiness of Social Networking Sites in the development of essential life skills. Parents believe that adolescents' level of awareness about the purpose of social networking sites and its usefulness is low. Parents claimed to know about the hours spent and sites visited by their wards. Parents agreed that the accessibility to data on Social Networking Sites should be limited and the policy terms and conditions of Social Networking Sites should be stringent. Parents agreed that their wards spend a major portion of their leisure time on Social Networking Sites that enable them to strike a balance between the real and virtual world and also decreases face-to-face communication.

\section{Conclusion}

The study aimed to gauge the attitude of parents, teachers and adolescents of the age of 16 years towards Social Networking Sites. In accordance with the findings of the study it can be concluded that Social Networking Sites have become one of the most popular mediums of communication among the adolescents. The boom in mobile technology has meant that most adolescents have easy access to smart phones, which allows easy access to these sites. Social Networking Sites offers an individual to keep updated with the latest information and at the same time keep in touch with the people all across the globe. Social Networking helps adolescents in maintaining social relationships and bonding with peers. Adolescents find it a comfortable way to communicate especially for the shy ones. This can help them in boosting their self-esteem and confidence. The correlation between the use of Social Networking Sites and social interaction of adolescents is high. It helps in mediating discussion portals among students and teachers. There is a 


\section{International Journal of Science and Research (IJSR) \\ ISSN (Online): 2319-7064 \\ Index Copernicus Value (2013): 6.14 | Impact Factor (2014): 5.611}

common belief among parents, teachers and adolescents, that the adolescents are not able to strike a balance between their Social Networking Sites and academics, this is due to the reason that they are not able to restrict themselves once they start surfing on these websites. This results in increased levels of stress and has a serious effect on adolescents' academic performance with a decreased face -to facecommunication. The security concerns regarding Social Networking Sites are also high among all the three groups as some of the adolescents as some of the adolescents have been a victim of cyber bullying. The attitude of parents, teachers and adolescents towards social networking sites is neutral. Social Networking Sites are both a boon and curse, depending upon the level of awareness pertaining to the different aspects like privacy and accessibility and the purpose for which they are being used.

\section{References}

[1] Kist, William.(2008). I gave up Myspace for Lent: New teachers and Social Networking Sites. Journal of Adolescent \& Adult Literacy, vol. 52, No.3,November pp. $245-247$

[2] Tuckman, H.P. (1975). Teacher Effectiveness and student performance. The Journal of Economic Education, 7(1): 34-39.

[3] Shah, D.V.\& Kwak, Nojin \& Holbert, R.L. (2001). Connecting and disconnecting with civic life: Patterns of Internet use and the production of social capital. Political Communication.18, pp.141-162.

[4] Jain, M.R. \& Gupta, Palak \& Anand, Nitika (2012). Impact of social networking sites in the changing mindset of youth on social issues - A study of Delhi NCR youth. International Refereed Research Journal, vol.-III, Issue 2(2), April, pp.36-43.

[5] Mehmood, Saba \& Tasvir, Tarang. (2013). The Effects of Social Networking Sites on the Academic Performance of Students in college of Applied Sciences, Nizwa, Oman. International Journal of Arts and Commerce. January. vol. 2 No. 1.

[6] Mahat, Shabnam \& Mundhe, S.D. (2014). Impact of Social Networking Sites (SNS) on the youth. National conference on Innovations in IT and Management ISBN. 978-81- 927230-0-6.

[7] Patil, Pranali (2014). Impact of Social Networking Sites (SNS) on the youth. Episteme: an online interdisciplinary, multidisciplinary and multicultural Journal. Volume 3, Issue, June.

[8] Cline, Laura (2012).The Impact of social Media on Adolescent Development. Issues in Human Development.

[9] Bhola, Reema \& Mahakud \& Gopal Chandra.(2014). A qualitative analysis of social networking usage. International journal of Research \& Development of Health., Vol 2(1) March, pp.34-44.

[10] Reid, Geordy \& Boyer, Wanda. (2013). Social Network Sites and Young Adolescent Identity Development, Childhood Education, 89:4, pp. 243-253.

\section{Author's Profile}

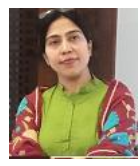

Dr. Anjali Shokeen, Assistant Professor, University School of Education, GGSIP University, Dwarka,
Delhi. She obtained Ph.D. degree from Jamia Millia Islamia, Central University in Delhi. She had almost 11 years of teaching experience as a Teacher Educator. Qualifications: M.COM, M.ED, MBA (HR), M.PHIL (EDUCATION). 